\title{
O trabalho do professor com crianças imigrantes e refugiadas: um estudo teórico do contexto brasileiro
}

\author{
Rômulo Sousa de Azevedo \\ Instituto Federal de Goiás - IFG, Brasil \\ Cláudia Tavares do Amaral \\ Universidade Federal de Catalão - UFCAT, Brasil
}

\begin{abstract}
RESUMO
O presente artigo tem como objetivo analisar a contextualização histórica da entrada de crianças imigrantes e refugiadas nas escolas brasileiras, bem como compreender as diferenças dessa entrada na contemporaneidade e o impacto gerado no trabalho docente. O texto está pautado nos pressupostos do materialismo histórico-dialético e foi estruturado em três partes: a) a historicidade da educação para imigrantes e refugiados nos séculos XIX e XX; b) reflexões sobre a presença de crianças imigrantes e refugiadas nas escolas entre 2010-2020, considerando: globalização, guerras e conflitos civis e desastres ambientais; e c) o impacto que essa presença acarreta ao trabalho docente. $\mathrm{O}$ eixo de conclusão é que a presença de crianças imigrantes e refugiadas nas escolas é uma realidade que modifica o trabalho docente quantitativa e qualitativamente. Para o professor atuar efetivamente, é necessário haver mudanças na formação inicial e no desenvolvimento de políticas públicas que subsidie o profissional.
\end{abstract}

PALAVRAS-CHAVE: Trabalho Docente. Migração. Formação Inicial. Políticas Públicas.

\section{TEACHER OF IMMIGRANT AND REFUGEE CHILDREN IN THE BRAZILIAN CONTEXT}

\begin{abstract}
The purpose of this article is to analyze the historical context of the entry of immigrant and refugee children in Brazilian schools. Consequently, we intent to understand the impact generated on teaching work in contemporary times. This article embrace the assumptions of historical dialectical materialism and is structured in three parts: a) the historicity of education for immigrants and refugees in the 19th and 20th centuries; b) reflections on the presence of immigrant and refugee children in schools between 2010-2020, considering globalization, wars and civil conflicts and environmental disasters; c) the impact generated on teaching work. We conclude that the presence of immigrant and refugee children in schools change the teaching work quantitatively and qualitatively. To improve the teacher work in these conditions the initial training should change and we need to develop public policies focused in support the professional.
\end{abstract}

KEY WORDS: Teaching Work. Migration. Initial formation. Public policy. 


\section{PROFESOR DE NIÑOS INMIGRANTES Y REFUGIADOS EN EL CONTEXTO BRASILEÑO}

\section{RESUMEN}

El artículo tiene como objetivo analizar la contextualización histórica del ingreso de niños inmigrantes y refugiados en las escuelas brasileñas, así como comprender las diferencias de este ingreso en el tiempo contemporáneo y el impacto generado en el trabajo docente. El texto se basa en los supuestos del materialismo dialéctico histórico y se estructuró en tres partes: a) la historicidad de la educación para inmigrantes y refugiados en los siglos XIX y XX; b) Las reflexiones sobre la presencia de niños inmigrantes y refugiados en las escuelas entre 20102020, considerando: globalización, guerras y conflictos civiles y desastres ambientales; c) el impacto que esta presencia tiene en el trabajo docente. La línea de conclusión es que la presencia de niños inmigrantes y refugiados en las escuelas es una realidad que cambia el trabajo docente cuantitativa y cualitativamente. Para que el docente actúe con eficacia, es necesario tener cambios en la formación inicial y el desarrollo de políticas públicas que apoyen al profesional.

PALABRAS CLAVE: Trabajo Docente. Migración. Formación inicial. Políticas públicas.

\section{INTRODUÇÃO}

O presente artigo visa apresentar uma discussão acerca do trabalho docente com crianças imigrantes e refugiadas nas escolas brasileiras ${ }^{1}$. De início, é necessário apresentar as definições de imigrante e refugiado para melhor compreensão do estudo.

De acordo com a Organização Internacional para Migrações (OIM) (2018), cerca de 3,3 \% da população mundial, em2017, foi composta de imigrantes e refugiados, dois grupos que compõem o movimento migratório, mas por razões distintas. Além desses, podemos citar outros grupos, como os migrantes e os emigrantes. De acordo com Delfim (2019), o termo migrante é utilizado para designar a pessoa que se desloca dentro de seu próprio país, mas também pode ser usado para retratar as migrações internacionais. No caso de imigrante, Delfim (2019) afirma ser essa a pessoa que se desloca de outro país para o Brasil, enquanto emigrante é quem deixa seu país de origem para viver em outro. O imigrante que chega aqui no Brasil, em seu país de origem é considerado um emigrante, e vice-versa.

Quando a OIM (2018) afirmou em seu relatório anual que, dos 244 milhões de migrantes no mundo, parte é composta de imigrantes econômicos, a organização se referiu às pessoas que saíram de seu país de forma voluntária, em busca de melhores oportunidades econômicas. A principal diferença entre o imigrante econômico e o refugiado consiste, então, na forma de migrar. Enquanto para o imigrante econômico a migração é voluntária, para o refugiado, é forçada.

\footnotetext{
${ }^{1} \mathrm{O}$ estudo foi desenvolvido por pesquisadores que integram a Rede de Pesquisadores sobre professores da Região Centro-Oeste/Brasil (REDECENTRO).
} 
É claro que, além do imigrante econômico, há outros grupos que migram de forma voluntária e por outras razões, como por questões familiares ou de estudos (OIM, 2018). Mas, mesmo nesses casos, os imigrantes também são colocados na categoria de migração econômica, pois há o aspecto econômico, que se torna relevante para os imigrantes e para a sociedade que os acolhe (LUSSI, 2015). Comumente, associa-se migração econômica à voluntária, no entanto, não é uma categoria rígida, pois a econômica pode estar ligada à migração forçada, como se verá adiante.

Em relação ao refugiado, a Lei brasileira $n^{\circ}$ 9.474, de 1997, também conhecida como o Estatuto dos Refugiados, traz a seguinte definição:

Art. $1^{\circ}$ Será reconhecido como refugiado todo indivíduo que:

I - devido a fundados temores de perseguição por motivos de raça, religião, nacionalidade, grupo social ou opiniões políticas encontra-se fora de seu país de nacionalidade e não possa ou não queira acolher-se à proteção de tal país; II - não tendo necessidade e estando fora do país onde antes teve sua residência habitual, não possa ou não queira regressar a ele, em função das circunstâncias descritas no inciso anterior;

III - devido à grave e generalizada violação de direitos humanos, é obrigado a deixar seu país de nacionalidade para buscar refúgio em outro país. (BRASIL, 1997).

O tema migratório é complexo, pois, além de englobar pessoas que provém de contextos migratórios diferentes, abrange instituições que passarão a trabalhar com esse público. Tal movimento não se trata apenas do deslocamento da pessoa de um país para o outro, mas também do "depois", de como será a vida cotidiana e a sua inserção na saúde, no trabalho, no lazer e na educação. Neste último caso, o foco se detém, sobretudo, nas crianças que migram com seus pais. E aqui reside um fato necessário de ser reiterado: crianças também migram! Seja com seus familiares, sejam sozinhas, crianças migram para outros países, o que demanda que áreas além daquelas ligadas ao trabalho, ao emprego e à ascensão social se organizem, a fim de acolher esse público (NORÕES, 2016).

A produção acadêmica que trata da relação entre professores brasileiros e alunos imigrantes e refugiados é ainda incipiente (FREITAS; SILVA, 2015), o que não quer dizer que essa realidade escolar não exista ou seja pouco frequente, ou ainda, que o tema não seja relevante. O Censo escolar de 2016 mostra que, entre 2008 a 2016, houve um aumento de $112 \%$ no número de matrículas de estrangeiros (imigrantes e refugiados) nas escolas brasileiras, com $64 \%$ dos estudantes se concentrando na rede pública de ensino. Nesse período, os estados que mais receberam alunos foram: São Paulo, 34,5\%; Paraná, 10,7\% e Minas Gerais, 10,6\% (HIROMI; GOIS, 2018). 
Entretanto, antes de falar da presença atual de imigrantes e refugiados nas escolas, é importante ressaltar que tal realidade não é nova, há um processo histórico por trás disso, que culmina no hoje e acarreta mudanças para o trabalho docente. É nesse cenário que o presente artigo tem como objetivo analisar a contextualização histórica da entrada de crianças imigrantes e refugiadas nas escolas brasileiras, bem como compreender as diferenças dessa entrada na contemporaneidade e o impacto gerado no trabalho docente. Para tanto, o texto está pautado nos pressupostos do materialismo histórico-dialético e foi estruturado em três partes: a) a historicidade da educação para imigrantes e refugiados nos séculos XIX e XX; b) reflexões sobre a presença de crianças imigrantes e refugiadas nas escolas entre 2010-2020, considerando: globalização, guerras e conflitos civis e desastres ambientais; e c) o impacto que essa presença acarreta ao trabalho docente.

Os textos com os quais dialogamos na segunda e na terceira parte deste artigo se fundamentam na perspectiva do materialismo histórico-dialético. Buscamos mostrar que determinadas situações não provêm de uma condição natural, mas de uma condição social marcada pelo caráter material, como o sistema escravista e a presença de imigrantes no Brasil, de forma intensa, desde o século XIX. Assim, ao partir da realidade histórica-empírica, analisamos o objeto de estudo pelo pensamento dialético para se chegar ao concreto pensado.

Para fundamentar a parte quatro do artigo, realizamos um levantamento bibliográfico na plataforma Google Scholar, pela qual optamos porque permite acesso a artigos publicados em revistas e anais de congressos, além de monografias, teses e dissertações. Para este trabalho, os critérios de inclusão foram artigos escritos em português, na temática da educação e da migração, publicados em periódicos acadêmicos e em anais de congressos na área da educação, com foco na educação básica - educação infantil e ensino fundamental. O levantamento se pautou em estudos sobre o trabalho docente com crianças advindas de fluxos migratórios, entre os anos de 2010 a 2020, período que fundamenta nossa análise das migrações contemporâneas, conforme será apresentado na terceira parte deste artigo.

Como parâmetro de exclusão, foram aplicados os seguintes critérios: a) trabalhos realizados na linha da História da Educação; b) trabalhos realizados em outras áreas de conhecimento, como Linguística e Ciências Sociais; c) trabalhos na área da Educação, mas fora do nosso escopo de análise; d) trabalhos sem acesso disponível. Como descritores, utilizamos os termos "professor", "criança imigrante", "escola", "criança refugiada".

Na primeira etapa da pesquisa, o resultado da busca apresentou dezenove trabalhos. Ao fazer uma leitura sistemática, identificamos cinco artigos que se relacionam com nosso escopo de estudo. Após a triagem, a segunda etapa consistiu em uma análise dos artigos que retratam 
o trabalho dos professores com crianças imigrantes e refugiadas, a partir do pensamento dialético.

\section{A HISTORICIDADE DA EDUCAÇÃO E DA MIGRAÇÃO NO BRASIL}

A presença de imigrantes no Brasil se confunde com a própria história do país. Uma semana após a promulgação da primeira Constituição Brasileira, D. Pedro I, em 31 de março de 1824 , assina a Decisão de $n^{\circ} 80$, em que ordena a demarcação de terras da colônia alemã de São Leopoldo - Rio Grande do Sul (VAINER, 2000), tendo aí um primeiro indicativo da presença de imigrantes europeus na ocupação do território brasileiro.

Outras iniciativas foram realizadas para o povoamento do país por imigrantes, em episódios que se fundem a momentos históricos, como a abolição da escravatura. A primeira grande onda migratória começou no século XIX, na substituição de força de trabalho: do homem escravizado (que agora, pela abolição, era "homem livre" ${ }^{2}$ ) para o imigrante europeu. A estratégia era enviar os trabalhadores estrangeiros para as fazendas de café, principal cultivo do período, espalhadas pelos estados de São Paulo, Minas Gerais, Rio Grande do Sul e Paraná. Essa política prevaleceu do século XIX até o final dos anos 40 e, apesar de se concentrar em trabalhadores europeus, o país recebeu uma grande quantidade de imigrantes japoneses (VAINER, 2000).

Percebe-se, assim, como o trabalho ${ }^{3}$ explica o processo migratório iniciado no século XIX, com período de amadurecimento no século XX. Com amplo apoio político, a migração europeia para o Brasil, motivada pelo trabalho, não foi de indivíduos, mas de grandes massas de população e está relacionado à própria mundialização do capitalismo (IANNI, 1987). E é através do trabalho que o fenômeno migratório se estende para outras áreas da sociedade, como a educação.

É necessário compreender que a história não é unilinear, evolutiva ou cronológica, ela possui caráter antagônico e, por isso, avança em um ritmo que sobrepassa o andamento cronológico e se abre para novas direções (IANNI, 1988). Foi o que aconteceu com a abolição da escravatura, afinal, agora livres, por que não contratar a população negra como trabalhadores assalariados? Além do passado de escravidão como marca estigmatizadora que a população

\footnotetext{
2 Mesmo após a abolição, diversos fazendeiros continuaram a manter pessoas escravizadas em suas terras (VAINER, 2000).

${ }^{3}$ A essência dos homens está no ato de se criar e se desenvolver pelo trabalho. Eles se diferenciam dos animais por produzirem seus meios de existência, e consequentemente, sua organização corporal "Ao produzirem seus meios de existência, os homens produzem indiretamente sua própria vida material” (MARX, ENGELS, 2001, p. 10-11).
} 
negra fora obrigada a suportar, ela não era vista pelos fazendeiros como devotas ao trabalho e esforçadas, características encontradas nos imigrantes europeus (MARTINS, 2010).

Diante desse cenário, o início do trabalho livre não foi o mesmo processo para a população negra que havia sido escravizada e para os trabalhadores europeus. Para estes, a mensagem passada era de que seriam donos da própria terra e poderiam gerar riquezas (MARTINS, 2010). Temos, com isso, o primeiro cenário de antagonismo: empregadores, em sua maioria grandes fazendeiros, movidos pelo racismo e pela perda de força de trabalho, rejeitam a população negra recém-liberta como trabalhadores livres e assalariados, colocandoos à margem da sociedade. É por meio desse antagonismo que o país se abre para os imigrantes.

Apenas no estado de São Paulo, de 1882 a 1885, a média anual de imigrantes foi de 4,8 mil; em 1886, o número já era de 9,5 mil; em 1887, 32,1 mil; e de 1888 a 1897, 68,5 mil, perfazendo o total de 727 mil imigrantes entre 1886 e 1897 (CANO, 2007). Em termos regionais, no Sul e no Sudeste houve um grande pluralismo étnico e cultural: foram portugueses, japoneses, alemães, espanhóis, italianos e poloneses, integrando-se, contribuindo e recebendo influências da sociedade (DEMARTINI, 2004; KREUTZ, 2000a). Em perspectiva nacional, Martins (2010) fala de mais de 1 milhão e 600 mil imigrantes num período de pouco mais de 30 anos, entre 1881 e 1913. Ianni (1987) vai além e diz que, até 1974, o país já havia recebido 5 milhões de imigrantes, com maiores contingentes da Itália, Japão, Espanha, Alemanha e da população árabe.

Por trás desses dados, a política migratória tinha duas intenções: a primeira era, por meio do trabalhador europeu, frutificar e fortalecer as grandes fazendas produtoras de café; e a segunda, disseminar pessoas brancas pelo país. O sociólogo Octavio Ianni (1987), na obra Raças e Classes Sociais no Brasil, afirma que os imigrantes europeus foram "escolhidos a dedo". A preferência era dada para alemães, italianos, poloneses, portugueses e espanhóis, com intenção explícita entre políticos e funcionários que buscavam eliminar ou reduzir a presença visível do negro e do mulato.

Para cumprir o propósito de branqueamento do país, a política migratória do século XIX foi criada para proibir a entrada de negros da África e de chineses. No caso destes últimos, apesar de disponíveis, foram preteridos por serem amarelos (IANNI, 1987). O Decreto $\mathrm{n}^{\circ} 528$, de 28 de junho de 1890, responsável por regular a política migratória, é explícito quanto a isso:

Art. $1^{\circ}$ É inteiramente livre a entrada, nos portos da República, dos indivíduos válidos e aptos para o trabalho, que não se acharem sujeitos à ação criminal do seu país, excetuados os indígenas da Ásia, ou da África que somente mediante autorização do Congresso Nacional poderão ser admitidos de acordo com as condições que forem então estipuladas (BRAZIL, 1890). 
Fica evidente que a presença de imigrantes no Brasil e, consequentemente nas escolas, devia-se a um nítido racismo por parte daqueles que elaboravam e conduziam a política migratória. Nesse meio, o negro, apesar da sua libertação, não era visto como um ser humano, mas como um objeto que havia perdido seu valor de propriedade (IANNI, 1987).

Para cumprir as intenções de força de trabalho para as fazendas e o branqueamento do país, havia necessidade de elaborar um discurso assimilacionista, buscando integrar os europeus à nacionalidade, torná-los solidários e fiéis ao Brasil. No entanto, o assimilacionismo teve uma forte oposição dos europeus, que não queriam perder ou mesclar suas culturas de origens com a cultura local. Tal oposição se deu, sobretudo, pela educação (VAINER, 2000), uma vez que cada grupo possuía uma tradição escolar. Enquanto espanhóis e portugueses estudavam em escolas brasileiras, as comunidades alemã, japonesa e italiana construíam escolas próprias para as crianças, a fim de preservar a cultura e a tradição do país de origem (DEMARTINI, 2004; KREUTZ, 2000b). O fato de haver escolas de imigrantes, também chamadas de escolas étnicas, produzia mudanças como as ocorridas em São Paulo:

\begin{abstract}
Apenas para exemplificar, lembramos que os imigrantes japoneses que começaram a chegar a partir de 1908, conviviam no Japão com as reformas implantadas pela dinastia Meiji (DEMARTINI, 1997). Dessa forma, já tinham acesso no Japão a uma escolaridade básica de seis anos, disseminada entre os habitantes rurais e os urbanos, e muitos já tinham atingido o ensino médio e o superior. Os provenientes de Portugal, entretanto, embora muitos também tivessem conseguido atingir esses níveis mais elevados, vinham de uma nação com sérios problemas na área educacional, em que o analfabetismo era muito elevado (DEMARTINI, 2001 b). Essas diferentes convivências com o campo educacional no país de origem certamente trouxeram implicações para a vivência educacional desses grupos em São Paulo. No caso dos japoneses, implicou que procurassem manter esta tradição de escolarização prolongada: logo ao chegar, e em decorrência também da inexistência de escolas em grande parte dos lugares para os quais se dirigiram, criavam escolas, geralmente segundo os padrões do sistema educacional japonês, embora procurassem respeitar a legislação nacional, restritiva às escolas "étnicas" desde a Primeira Guerra Mundial (DEMARTINI, 1998a) (DEMARTINI, 2004, p. 2019).
\end{abstract}

Contraditoriamente ao discurso assimilacionista, um dos fatores que levou à disseminação das escolas étnicas foi a dificuldade do governo brasileiro em ofertar escolas públicas e professores capacitados. Na década de 1890, o período mais intenso da imigração, o sistema escolar brasileiro era altamente deficitário, cerca de $80 \%$ da população era analfabeta (KREUTZ, 2000b) e, não havendo condições ou vontade política para a oferta de escolas, o governo, mesmo de maneira forçada, estimulou os imigrantes na abertura das escolas.

Na América, o Brasil foi o país com o maior número de escolas étnicas (KREUTZ, 2000b), em 1913, havia 396 escolas italianas em todo o país. Apenas a cidade de São Paulo, em 
1917, tinha 272 escolas particulares, sendo 101 étnicas (DEMARTINI, 2004). Já no início da década de trinta, havia no Brasil 349 escolas polonesas, 178 escolas japonesas e 1.579 escolas alemãs (KREUTZ, 2000b). Somente no Rio Grande do Sul, o número de escolas alemãs chegou a 1.041 instituições (KREUTZ, 2000a).

Além da diversidade numérica das escolas étnicas, Kreutz (2000b) destaca as distinções que havia entre elas: comunitárias, particulares de congregações religiosas, particulares laicas urbanas e particulares em área rural. Como decorrência do fenômeno, várias mudanças foram introduzidas na contratação de professores, nas propostas curriculares e na cultura escolar (DEMARTINI, 2004).

A partir de 1930, escolas públicas passaram a ser abertas próximas às étnicas. Posteriormente, com uma política nacionalista, o governo restringiu a abertura de novas escolas étnicas e, nos anos 1938 e 1939, em um movimento de nacionalização compulsória, todas elas foram fechadas ou transformadas em escolas públicas, por meio de decretos de nacionalização (KREUTZ, 2000a). Ianni (1987), inclusive, denomina esse ato de "política de nacionalização forçada", com a supressão do ensino de línguas e a substituição de professores estrangeiros por brasileiros.

Pode-se demarcar, a partir desse período, a forte presença de alunos imigrantes nas escolas brasileiras e o desfecho de mais um antagonismo, agora entre a classe política brasileira, com planos nacionalistas, e os diversos grupos de imigrantes que presenciam o fechamento de suas próprias escolas. Nesse contexto, há mais um "salto" na historicidade, dessa vez com impacto nas escolas brasileiras, devido à presença mais constante de alunos estrangeiros.

Referente ao envolvimento dos professores brasileiros com os alunos, Demartini (2004) afirma que, nas escolas étnicas, por imposição da política brasileira, exigia-se a presença de pelo menos um professor brasileiro, o que, por sua vez, contribuía para uma extensa troca cultural e educacional. Nas escolas brasileiras, após o fechamento das escolas étnicas, Demartini (2004) aponta a convivência entre alunos e professores de diversas línguas nas escolas de São Paulo: podia-se ouvir nos corredores várias línguas: português, italiano, alemão, japonês, iídiche, russo e grego.

Podemos concluir que, se hoje há alunos imigrantes e refugiados nas escolas, esse processo começou no século XIX, com a expansão do território brasileiro, o fim do sistema escravista, a entrada de imigrantes europeus no país para o trabalho nas lavouras de café, a política de branqueamento, a construção de escolas étnicas e a aplicação de políticas nacionalistas que, posteriormente, forçaram o fechamento dessas escolas, acarretando na entrada, em grande proporção, de crianças imigrantes nas instituições brasileiras. 
Feita essa primeira análise histórica, é necessário compreender a perspectiva contemporânea, pois os movimentos migratórios não se extinguiram, ao contrário, tornaram-se mais frequentes. Os motivos da migração também aumentaram, e as próprias populações que agora migram não são as mesmas que migraram nos séculos XIX e XX. Dessa forma, passamos a analisar os movimentos migratórios contemporâneos, tendo como linha do tempo o período de 2010 a 2020, buscando compreender a existência desses fluxos para o Brasil, que, por consequência, acarretam na entrada de alunos estrangeiros nas escolas locais.

Escolhemos 2010 como o ano inicial por ter sido o ano em que o Brasil recebeu uma grande quantidade de haitianos, devido a um terremoto que atingiu o país no mesmo período, e 2020 como o ano final, em razão do extenso número de venezuelanos que têm adentrado o país, com início em 2014. Nesse mesmo período, temos também a migração síria, derivada da guerra civil iniciada em 2011, além dos movimentos migratórios de outras nacionalidades, mas com menor ênfase da mídia local.

\section{MIGRAÇÃO NA CONTEMPORANEIDADE: ALGUMAS EXPLICAÇÕES PARA A PRESENÇA DE ALUNOS ESTRANGEIROS HOJE}

Começamos falando do aspecto econômico que não pode ser desconsiderado do movimento migratório. Como explica Lussi (2015), as causas econômicas, também chamadas de labour migration ou migrations de traval, são constantemente utilizadas para explicar os fluxos migratórios que não são desencadeados por guerra ou desastres naturais e, por isso, têm sido consideradas, tradicionalmente, como migrações econômicas.

Entre as teorias econômicas que explicam a migração, iremos nos ater à World Systems Theory, que é ligada às ideias de Karl Marx sobre o funcionamento do capitalismo internacional. Segundo Lussi (2015), essa teoria defende que as origens da migração são identificadas nos desequilíbrios causados pelo sistema capitalista mundial que ocorrem por meio das intervenções dos Estados ${ }^{4}$. Sobre isso, Marx e Engels (1998, p. 11-12) afirmam no Manifesto Comunista:

A indústria moderna estabeleceu o mercado mundial, para o qual a descoberta da América havia aberto caminho. Este mercado desenvolveu enormemente o comércio, a navegação, a comunicação por terra. Este crescimento afetou novamente a extensão da indústria; e na mesma medida em que a indústria, o comércio, a navegação e as estradas de ferro se estendiam, a burguesia se

\footnotetext{
${ }^{4}$ Na Crítica do Programa de Gotha, Marx (2012) afirma que os Estados de vários países, apesar das diferenças, têm em comum o fato de estarem firmados sobre a base da sociedade burguesa, e é por estarem firmados nessa base que os Estados possuem certas características comuns que os tornam ligados ao sistema capitalista mundial.
} 
desenvolvia, aumentava seu capital [...] A burguesia, afinal, com o estabelecimento da indústria moderna e do mercado mundial, conquistou para si própria, no Estado representativo moderno, autoridade política exclusiva.

Em outro excerto, Marx e Engels enfatizam a necessidade de a burguesia expandir constantemente seus produtos por toda a superfície do globo: "Precisam instalar-se em todos os lugares, acomodar-se em todos os lugares, estabelecer conexões em todos os lugares" (MARX, ENGELS, 1998, p. 14). Segundo Ianni (1982), a questão não é apenas sobre a expansão do capitalismo, mas que, por meio dela, há uma generalização das relações humanas. O sistema capitalista mercantiliza as relações das pessoas e, ao mesmo tempo, mercantiliza as próprias pessoas. Ao dominar os povos da Ásia, África e América Latina, o capitalismo criava um mundo à sua imagem. Em um sistema frenético como esse, as consequências não tardariam a surgir, sendo a migração uma delas.

Posteriormente, Hobsbawm (2007) atualiza a teoria colocando em destaque a globalização que, acompanhada de mercados livres, trouxe um aprofundamento das desigualdades econômicas e sociais no interior das nações e entre elas. Bauman (2017, p. 9) afirma que o modo de vida da sociedade, modificado pela globalização, passou a incluir a produção de pessoas "localmente 'inúteis', excessivas ou não empregáveis, em razão do progresso econômico". Kurz (2005), por sua vez, diz que, devido à globalização, cada vez mais pessoas são tidas como "supérfluas", por não conseguirem vender sua força de trabalho:

Muitas grandes fábricas e, ainda mais, pequenas empresas caem abaixo do nível de produtividade determinado pelo mercado mundial, tornam-se nãorentáveis e, por isso, mais cedo ou mais tarde, são fechadas. Em lugar de um sistema que cubra o mundo todo com trabalho assalariado e valorização, vai surgindo um capitalismo insular: no mundo inteiro, a reprodução capitalista se reduz a "ilhas", ou melhor, "oásis" da produtividade e rentabilidade, em volta dos quais surgem desertos econômicos. Como consequência, reduzem-se violentamente as receitas estatais; grandes partes das infraestruturas são abandonadas ou estão direcionadas à reduzida produção dos "oásis". Estes têm uma densidade maior em determinados países e regiões dos centros capitalistas, enquanto no Leste e no Sul são menos densos e em algumas regiões mundiais nem existem mais. A própria produção de mercadorias deixa de integrar grandes massas da produção global. Os "supérfluos" estão sendo expelidos para circuitos subordinados, seja como empresários da miséria na circulação (ambulantes), como catadores de lixo, seja como força de trabalho doméstica barata; ou, então, caem em miserabilidade absoluta (KURZ, 2005, p. 27).

Marx e Engels (2001) concebem que a essência do homem está assentada no trabalho, é a partir dele que o homem cria sua própria vida e desenvolve sua criatividade, por meio daquilo que produz. No entanto, com o capital, o homem perde sua essência criadora, não se realiza mais em sua atividade, ocorre assim, a alienação. A globalização ampliou o fenômeno da alienação a escalas mundiais e, dado que o trabalhador pobre já não supre as demandas do capital em seu 
país, ele irá migrar para outro. Kurz (2005) afirma que os atuais movimentos migratórios são produzidos, em grande parte, por cegos processos econômicos e políticos, o que gera uma migração em massa, designada pelo autor como uma migração socioeconomicamente forçada.

Vale aqui uma reflexão: as pessoas com escassos recursos financeiros, que migram de seus países para outros em busca de melhores oportunidades econômicas, e que veem nisso a última opção, pois vivem em condições de pobreza, e em alguns casos de pobreza extrema, também não seriam forçadas a migrar? Também não seriam elas refugiadas? Não há lei que as respaldam nesse sentido, mas elas também não se equiparariam a outros casos de migração forçada? Um exemplo são os imigrantes bolivianos que residem em São Paulo, muitos saem da Bolívia em busca de melhores oportunidades de trabalho, mas chegam na cidade e encontram uma situação ainda mais agravante, com trabalho sendo feito em condições de escravidão, principalmente nas oficinas têxteis (SILVA, 2006; MARINEIS, 2015). Como Bauman (2017) afirma, em países onde tanto imigrantes econômicos como refugiados buscam abrigo, empresários desejam e dão boas-vindas ao fluxo de mão de obra barata e às habilidades lucrativamente promissoras.

A segunda explicação para a presença de crianças advindas de fluxos migratórios na escola reside nas guerras e conflitos civis. Como exemplo ilustrativo, destacamos o caso da Venezuela, que tem atravessado um conflito civil motivado por uma crise política, econômica e humanitária, criando uma combinação de fatores que têm forçado os cidadãos a deixarem seus lares, incapazes ou sem desejo de voltar (BRONER, 2018). Segundo o Alto Comissariado das Nações Unidas para Refugiados (ACNUR) ${ }^{5}$ (2019), até o mês de fevereiro de 2019, o número de refugiados e imigrantes da Venezuela era de 3,4 milhões de pessoas. Devido ao difícil contexto que o país vive, o êxodo venezuelano já é apontado como a maior crise migratória na história da América Latina (BRONER, 2018).

Esses dados mostram a força que guerras e conflitos civis têm para gerar grandes movimentos migratórios, afetando homens, mulheres, jovens e crianças. De acordo com o Relatório Global Missing Out: Refugee Education in crisis, publicado em 2016, pelo ACNUR, até 2016, havia 16,21 milhões de refugiados no mundo. Desse número, mais da metade era de crianças e seis milhões estavam em idade escolar primária e secundária, sendo que 3,7 milhões não estavam na escola: as crianças refugiadas têm cinco vezes mais probabilidade de estar fora da escola que as crianças não refugiadas. À medida que crescem, a dificuldade de inserção escolar se agrava. $84 \%$ dos adolescentes não refugiados frequentam a escola, mas somente $22 \%$ dos adolescentes refugiados têm a mesma oportunidade.

\footnotetext{
${ }^{5}$ Em inglês, lê-se, The UN Refugee Agency - UNHCR.
} 
Além disso, não podemos desconsiderar o trabalho do professor com alunos que provém de uma realidade de vida tão específica, como é no contexto de migração forçada:

Um professor que administra uma sala de aula que inclua alunos refugiados entrará, talvez, na sala de aula mais difícil do mundo. Entre a turma estarão crianças que viram suas casas destruídas e seus familiares feridos ou mortos. Alguns podem ter deficiências, seja desde o nascimento ou como resultado da violência em seus países de origem. Pode haver uma ex-criançasoldado, uma sobrevivente de abuso sexual, alguém que fez a viagem de fuga com segurança quando seu irmão ou sua irmã não a fizeram. Sua educação pode ter sido interrompida por semanas, meses ou até anos. Em média, o ACNUR estima que os refugiados perdem de três a quatro anos de escolaridade por causa do deslocamento forçado. A sala de aula provavelmente ficará lotada, mesmo que a escola opere em um sistema de turnos duplos, com crianças do país anfitrião se atracando com os refugiados. Esses acordos permitem que mais crianças frequentem a escola, mas as longas jornadas sobrecarregam os professores e outros funcionários. Em alguns países, as aulas podem ser ministradas em uma língua que as crianças refugiadas estão apenas começando a entender. No entanto, esta sala de aula pode transformar as crianças. Elas podem aprender leitura, escrita e matemática, a base da aprendizagem ao longo da vida, e elas podem aprender a aprender. Isto sustenta um maior desenvolvimento em linguagem, literatura e matemática, bem como nas ciências, geografia, história, estudos religiosos e outros assuntos quando as crianças se mudam para o ensino secundário e além. Além de disciplinas acadêmicas, elas podem aprender sobre cuidados básicos de saúde e higiene, cidadania, direitos humanos e onde, como e de quem obter ajuda. Desde as primeiras lições até a universidade, a educação ajuda os refugiados a se manterem em pé, permitindo que se preparem para o futuro, seja em um país anfitrião ou em seu próprio país, quando retornam (ACNUR, 2016, p. 14 - tradução nossa).

Ensinar uma criança refugiada, ou mesmo uma criança que migra com sua família de forma voluntária, tem suas particularidades: língua, cultura, saberes próprios, traumas. Além disso, as motivações econômicas e políticas geram guerras e conflitos civis, mas são causas acompanhadas de outras variáveis, como as diferenças religiosas, étnicas, sociais e culturais. Apreender a totalidade da situação é necessário para compreender os impactos na vida dos cidadãos em sua terra de origem, como também na sociedade receptora e no ambiente em que essas pessoas estarão inseridas. Dessa forma, tem-se o cenário em que uma criança da Venezuela começa a estudar em uma escola de bairro de uma cidade brasileira, com uma professora que até então nunca havia cogitado a possibilidade de ter um aluno refugiado. A vida de ambos se liga por um conflito civil.

Por fim, a terceira explicação para que o professor tenha crianças imigrantes e refugiadas em sala de aula, concentra-se nos desastres ambientais. Segundo Ramos (2011), a mobilidade gerada por alterações ambientais é, via de regra, forçada, irregular e coletiva. Temporária ou permanente, a migração ocorre interna e externamente. Pode ser "reativa", após a ocorrência 
das alterações ambientais que ameaçam a vida e a segurança humana, e "proativa", devido a processos graduais de deterioração ambiental. Um exemplo de migração por forças ambientais é o terremoto que atingiu o Haiti em 2010, afetando toda uma população que já era fragilizada devido à situação socioeconômica.

De acordo com a ONU (2010), antes do terremoto, $55 \%$ dos haitianos viviam com pouco mais de um dólar por dia e renda per capita anual de U\$660,00. O país, em 2009, estava no $149^{\circ}$ lugar, entre 182 países, no Índice de Desenvolvimento Humano (IDH), e mais de 60\% das crianças e $46 \%$ das mulheres sofriam de alguma forma de anemia, enquanto $58 \%$ das crianças estavam subnutridas.

Com o terremoto, considerado como o mais forte dos últimos 200 anos, a situação do Haiti ficou ainda mais delicada. A ONU estimou que 222 mil pessoas morreram, 300 mil foram feridas e 2,3 milhões foram deslocadas para outras áreas, incluindo 302 mil crianças. Estimase, ainda, que 1,5 milhão de crianças e jovens abaixo de 18 anos foram afetados direta ou indiretamente pelo tremor (ONU, 2010).

O fluxo migratório que já vinha acontecendo, após o terremoto se intensificou, afetando não apenas os países vizinhos, como a República Dominica, mas também nações distantes, dentre elas, o Brasil (ONU, 2010). No entanto, apesar da intensificação do fluxo migratório para o Brasil e do caráter humanitário presente na respectiva situação, os haitianos não poderiam ser considerados refugiados, por não estarem dentro do conceito definido pela Lei $\mathrm{n}^{\circ}$. 9.747 de 1997, uma vez que a migração forçada não ocorreu por perseguições ou violação contra os direitos humanos.

A solução encontrada pelo governo brasileiro foi a criação do visto humanitário. Assim, os haitianos não podem ser considerados refugiados, mas imigrantes portadores de visto humanitário, dessa forma, além de permanecer legalmente no país, o haitiano tem acesso a documentos de identidade, carteira de trabalho, acesso a serviços públicos de saúde e educação (GODOY, 2011). O resultado dessa ação pode ser percebido nos números do relatório “Diagnóstico regional sobre migración haitiana”, emitido pela OIM (2017): o Brasil recebeu, até 2016, o total de 67.226 haitianos.

Posteriormente, a variável motivacional da migração haitiana deixou de ser apenas a climática e passou a prevalecer, também, questões políticas, econômicas e sociais. Houve no país, entre 2018 e 2019, uma série de manifestações pedindo a renúncia do presidente Jovenel Moise, além de protestos contra a corrupção e a presença do governo no estabelecimento de serviços sociais para a população carente. Apenas entre setembro e novembro de 2019, mais de 42 pessoas foram mortas e centenas se feriram nas manifestações (MORALES, 2019). Consequentemente, a migração haitiana para o Brasil continua constante, visto que, dados do Ministério da Justiça e Segurança Pública 
mostram que, em 2018, 7.030 haitianos deram entrada no processo de solicitação de reconhecimento da condição de refugiados, dessa vez, por violações contra os direitos humanos.

\section{POLÍTICAS PÚBLICAS E FORMAÇÃO INICIAL: AÇÕES DE SUBSÍDIO PARA O PROFESSOR}

Em resumo, o fluxo migratório trata do deslocamento de pessoas, que ocorre de forma forçada ou voluntária. No entanto, apesar do fenômeno ser, em primeiro lugar, um processo de deslocamento de pessoas no espaço físico, não se prende apenas a esse aspecto, ocorre também em um espaço subjetivo, dotado de sentidos sociais, econômicos, políticos e culturais (SAYAD, 1999), ou seja, a pessoa não se desloca apenas no sentido geográfico. Ao adentrar nos espaços da nova cidade, como a escola, haverá um processo de deslocamento subjetivo. A título de exemplo, Payet (2011) fala da França da década de 70, nesse período, o país concebia a migração como um fenômeno polêmico, instrumentalizado nos debates públicos e nas campanhas políticas, em que o imigrante era apresentado sob uma dimensão negativa, de ameaça para a identidade nacional. Era nesse espaço que a criança imigrante adentrava nas escolas francesas, o que tornava comum casos de discriminação de professores com os alunos, estigmatização de escolas com forte concentração de crianças imigrantes e segregação sócio étnica escolar. Entretanto, tentativas de amenizar a situação foram bloqueadas pela administração escolar francesa.

Cada um dos espaços onde o imigrante e o refugiado adentram demanda um olhar específico, em nosso caso, voltamo-nos para a relação entre educação e migração. A criança proveniente de fluxos migratórios, ao chegar em uma cidade brasileira, não restringe seu espaço de atuação apenas à casa, ela precisará ampliá-lo, a começar pela escola. À medida que ganha novos espaços, a criança se molda, transforma-se, e é na escola que ela irá se deparar com mais intensidade às diferenças culturais, linguísticas, relacionais, de ensino e de aprendizagem.

Para além das transformações que irão ocorrer na criança, sua presença traz mudanças ao professor, desde sua compreensão sobre a figura do imigrante e do refugiado, até questões sobre como ensinar, comunicar e relacionar com o novo aluno. Dessa forma, afirmamos que a escola está em um processo de transformação provocado por fluxos migratórios, uma transformação que não é rápida, mas que acontece com alterações quantitativas e qualitativas nas salas de aula. Quantitativas porque o que seria uma sala com 20 ou 30 crianças brasileiras, agora é uma sala com 20 ou 30 crianças, dentre as quais, brasileiras, bolivianas, venezuelanas, haitianas. Qualitativas porque haverá "saltos", modificações no processo de ensinoaprendizagem, envolvendo o professor brasileiro e os alunos brasileiros e estrangeiros, as quais 
podem ocorrer na forma de se comunicar, com o uso de aplicativos de tradução simultânea; no envolvimento dos saberes das crianças estrangeiras na sala de aula; na adaptação curricular, para que haja conteúdos que se conectem à realidade dos novos alunos; e na interação entre as crianças estrangeiras e crianças brasileiras.

Diante disso, o professor tem um papel importante enquanto sujeito na garantia do direito à educação para crianças imigrantes ou refugiadas, pois é ele quem cria o elo entre o saber escolar e a criança. Entretanto, não podemos desconsiderar instituições que podem auxiliá-lo com ferramentas e conhecimentos para a execução desse direito, quais sejam: o Estado, nas esferas estadual e municipal; e as universidades.

Quando se trata de educação e migração, a legislação existente sobre o tema é, na maioria, de amplitude federal: Constituição Federal de 1988, artigo 5º ; Estatuto da Criança e do Adolescente, $\operatorname{artigos} 3^{\circ}$ e $4^{\circ}$; Lei de Diretrizes e Bases da Educação Nacional, $\operatorname{artigos} 2^{\circ}$ e $3^{\circ}$; Estatuto do Refugiado, artigos $43^{\circ}$ e $44^{\circ}$; Lei de Migração no $13.445 / 2017$, artigos $3^{\circ}$ e $4^{\circ}$. Em âmbito estadual e municipal, a existência de leis que apoiem a criança imigrante e/ou refugiada e, principalmente, o professor, não acompanha a realidade existente na esfera federal.

É importante o envolvimento do poder público estadual e municipal na elaboração de políticas educacionais que ampliem a possibilidade de imigrantes e refugiados se envolverem com a educação formal, e na institucionalização de sistemas de suporte e formação para o professor que irá atuar com essas crianças. Para fins de exemplificação, citamos o caso da Coordenação de Políticas para Migrantes, uma instância dentro da Prefeitura Municipal de São Paulo, localizada na Secretaria de Direitos Humanos. Em 2013, o órgão criou um evento para estabelecer diálogo entre a prefeitura, as diversas comunidades de imigrantes e refugiados e as entidades envolvidas com a temática, cuja intenção era que tanto as comunidades como as entidades pudessem expor suas reivindicações. Ligadas à educação, foram pautadas denúncias sobre maus-tratos, impossibilidade de matrícula, bullying, dificuldade de acesso às instituições públicas, necessidade de criação de escolas multilíngues e multiculturais e garantia de vagas em concurso público para professores de outros países (NORÕES, 2016).

Questões como impossibilidade de matrícula, bullying e acesso às instituições escolares são tópicos que podem ser utilizados pela prefeitura para auxiliar professores na resolução de problemas: fornecer melhores orientações para a matrícula de imigrantes e refugiados; estabelecer equipes disponíveis na secretaria de educação para capacitar professores a lidarem com bullying, preconceito e racismo que alunos imigrantes e refugiados possam vir a sofrer. Diante disso, fica evidente que o professor atua para garantir o direito à educação da criança que provém de fluxos migratórios, mas há uma instituição por trás que respalda e subsidia suas ações. 
Em 2016, a cidade de São Paulo instituiu a Política Municipal para a População Imigrante e o Conselho Municipal de Imigrantes, pautadas pela Lei 16.478/2016. No artigo $7^{\circ}$, é apresentada a seguinte afirmação:

Art. $7^{\circ}$ - São ações prioritárias na implementação da Política Municipal para a População Imigrante [...] IV - garantir a todas as crianças, adolescentes, jovens e pessoas adultas imigrantes o direito à educação na rede de ensino público municipal, por meio do seu acesso, permanência e terminalidade (SÃO PAULO, 2016).

Junto à Política Municipal para a População Imigrante, a Secretaria Municipal de Educação de São Paulo dispõe, também, do Núcleo de Educação Étnico-racial (NEER). No sítio eletrônico do núcleo consta a seguinte apresentação:

O Núcleo para a Educação das Relações Étnico-Raciais - NEER tem como objetivo implementar as Diretrizes Curriculares Nacionais para a Educação das Relações Étnico-Raciais e para o Ensino de História e Cultura Afrobrasileira e Africana nos estabelecimentos de ensino da Rede Municipal de Ensino de São Paulo por meio da formação continuada de professores e gestores, tendo por base a educação para a convivência e o ensino para a aprendizagem e produção de conhecimento sobre história e cultura afrobrasileira, indígena, imigrante e latino-americana.

O NEER se concentra em três áreas de trabalho: História e Cultura Africana e AfroBrasileira; História e Cultura Indígena e Educação Escolar Indígena; Educação para Imigrantes e Educação para Populações em Situação de Itinerância. No que concerne à terceira área de trabalho, uma das funções do NEER é ofertar formação continuada para professores e gestores que trabalham com imigrantes, sendo assim, há uma lei municipal que está em consonância com a lei federal no tocante ao direito à educação ao público advindo de fluxos migratórios, e uma equipe específica da Secretaria Municipal de educação para auxiliar professores a atuarem nessa realidade.

Além de São Paulo, outras cidades e estados têm feito ações semelhantes. Araújo e Contreras (2017), no artigo A criança imigrante e a escola: adaptação social e curricular, estudo que trata da adaptação social e curricular de crianças imigrantes em escolas públicas de Curitiba, relatam sobre a existência de uma equipe específica da Secretaria Municipal de Educação para orientar os professores a receberem os alunos imigrantes. No trabalho de Alexandre (2017), “Aquela preta não é minha amiga!”: Interações e Socialização de Crianças Haitianas nas Escolas de Educação Infantil em Sinop/MT, um estudo que investiga o processo de inserção escolar de crianças haitianas nas instituições educacionais de Sinop, cidade do Mato Grosso, a autora fala de um processo seletivo realizado pela Secretaria de Educação do Estado do Mato Grosso, em 2017, para técnico de atendimento especial para a língua crioulo, que é a 
língua nativa do Haiti. Duas escolas de Sinop requisitaram vagas: uma estadual de ensino fundamental e uma municipal na modalidade de Educação de Jovens e Adultos (EJA). Os técnicos auxiliariam alunos e professores na comunicação e no processo de ensinoaprendizagem de conteúdo.

Os trabalhos de Araújo e Contreras (2017) e Alexandre (2017) evidenciam a importância dos estados e dos municípios na defesa do direito à educação para a criança imigrante e refugiada e no suporte aos professores que estão em sala de aula. No entanto, os exemplos apresentados são exceção e não regra. Sem o respaldo das três esferas do governo, o professor se encontrará em uma situação que demandará mais esforço e dedicação, mesmo que não tenha preparo e conhecimentos para lidar com tal realidade, o que pode afetar quantitativa e qualitativamente seu trabalho.

O artigo de Schmidit, Piccinini e Volkmer (2016), O acesso à educação aos imigrantes haitianos em uma escola pública de Arroio do Meio, apresenta a inserção escolar de crianças haitianas em uma escola pública. Nesse trabalho, as autoras constataram que os professores não tinham uma equipe para auxiliá-los, a própria escola, entre erros e acertos, desenvolveu os procedimentos necessários para a recepção e a inclusão das crianças, mas o resultado foi positivo, sobretudo devido ao esforço conjunto dos professores, pois não receberam treinamento por parte da Secretaria Municipal de Educação ou orientação prévia sobre como acolher e trabalhar com os imigrantes. Conforme Schmidit, Piccinini e Volkmer (2016) afirmam, isso torna o sistema altamente frágil, o que as leva a concluir que, em outras localidades, a realidade poderia ser distinta e a inclusão poderia não ocorrer da mesma forma que na escola analisada.

Freitas e Silva (2015) no artigo Crianças bolivianas na educação infantil de São Paulo: adaptação, vulnerabilidades e tensões, destacam que, apesar de haver uma presença marcante de crianças bolivianas no cotidiano da educação infantil em São Paulo, as professoras se sentiam desamparadas diante da tarefa de trabalhar com elas, algo caracterizado pelos autores como uma solidão docente. Devido à falta de orientação e formação específica, o contexto de ensino apontava para situações de tensão como o desconhecimento das professoras sobre a cultura das crianças bolivianas e dificuldades entre professoras e alunos no processo de comunicação.

No trabalho de Assumpção e Aguiar (2019), "Você precisa falar português com seu filho" Desafios para o processo de inclusão de crianças imigrantes em escolas do Rio de Janeiro, as autoras destacam que, ao mesmo tempo que há um avanço legislativo sobre o tema, contraditoriamente, no cotidiano da escola, não há um trabalho que fundamente as ações do professor com as crianças: 
Os imigrantes sofrem pela falta de um planejamento pedagógico coerente com suas necessidades, e, apesar de poderem se matricular, o que encontram na maior parte das vezes, são escolas que não possuem professores com formação adequada para este atendimento. Pode-se afirmar que, segundo especialistas da área, temos uma legislação avançada, entretanto, não garante que, na prática, as crianças tenham seu direito garantido de forma inclusiva e não somente com a garantia de uma vaga na escola (ASSUMPÇÃO; AGUIAR, 2019, p. 8).

Nosso argumento é que, por mais que haja leis federais que garantem a educação para crianças imigrantes e refugiadas, em âmbito estadual e municipal essa realidade não é acompanhada. Haverá, então, um professor que, geralmente, não terá conhecimentos sobre o tema, pois não o estudou na formação inicial, nem respaldo de políticas educacionais ou ações promovidas pela secretaria de educação local. O docente, em alguns casos, poderá ser amparado pela equipe diretiva de sua escola, mas, ainda assim, em um processo de tentativas, erros e acertos. A consequência disso é a possível ocorrência de um processo de culpabilização do professor, no caso de evasão escolar, reprovação ou má assimilação de conteúdos pela criança.

A discussão pode ser ampliada para desenvolver o seguinte raciocínio: se o professor não possui respaldo da Secretaria de Educação para o trabalho educativo com alunos advindos de fluxos migratórios, qual processo formativo poderia dar condições a ele? A resposta reside na formação inicial (ASSUMPÇÃO; AGUIAR, 2019), e entendemos que somente ela não consegue abarcar toda a complexidade do ambiente e do processo educacional, mas crianças imigrantes e refugiadas fazem parte da realidade escolar brasileira, logo, defendemos a tese de que a formação pode contemplar esse aspecto se, por exemplo, ocorrer como componente curricular optativo $^{6}$, integrando parte da formação inicial, além de ações que envolvam estudantes da formação inicial em estágios com professores que trabalham com crianças imigrantes e refugiadas.

O professor possui um papel preponderante, pois ele estará à frente do ensino de alunos que provêm de outros países, todavia, deve-se ter cuidado para não incorrer na culpabilização desse profissional, sujeito a uma realidade nova e distinta, diante da qual, muitas vezes, não saberá como agir, já que não obteve formação ou orientação nesse sentido. Para que o professor desenvolva o trabalho educativo buscando a formação humana de seus alunos, o processo passa por ele, mas não se inicia nele. Há instituições que devem respaldá-lo com conhecimentos e ferramentas, em especial, o poder público, nos âmbitos estadual e municipal, com formações continuadas e equipes de apoio para os professores; e as universidades, trazendo o tema para a

\footnotetext{
${ }^{6}$ Disciplinas optativas ofertadas na Universidade possibilitam ao discente uma autonomia para a construção de seus saberes, ultrapassando a matriz curricular estabelecida para sua formação.
} 
formação inicial, por meio de componentes curriculares optativos ou cursos livres que envolvam parcerias com escolas, atividades de extensão e/ou estágios.

\section{CONSIDERAÇÕES FINAIS}

Ao identificar a realidade e a especificidade do aluno oriundo de fluxos migratórios, compreendemos que, se hoje eles estão nas escolas, esse processo começou no século XIX e perdurou até meados do século XX, com a expansão do território brasileiro, o fim da escravidão, a entrada de imigrantes europeus nas grandes lavouras de café para substituir o trabalho escravo, a política de branqueamento do país, a construção de escolas étnicas e a aplicação de políticas nacionalistas que, posteriormente, forçaram o fechamento dessas escolas, acarretando na entrada, em grande proporção, de crianças imigrantes nas instituições brasileiras. Demarcamse então, nesse período, as grandes ondas migratórias para o país e as primeiras relações entre os campos da educação e da migração.

Quando avançamos no tempo para tratar da contemporaneidade, é possível verificar que o movimento migratório sofreu várias mutações. Se entre os séculos XIX e XX predominava a migração econômica com presença maciça de europeus, entre 2010-2020, o movimento migratório passou a ser justificado por três razões: globalização, guerras e conflitos civis e desastres ambientais, com a predominância não somente de imigrantes, como de refugiados. Para além disso, a migração deixa de ser centralizada na Europa e se pulveriza para outros continentes, como a América Latina.

Toda essa linha histórica nos mostra como o tema é atual e como a educação foi sendo afetada ao longo dos anos. Se antes o professor brasileiro ensinava crianças provenientes de países europeus, em condição de migração voluntária, agora, ele se encontra na situação de ensinar crianças que estão na sala de aula por uma condição de migração forçada, oriundas de países que passaram por guerras, conflitos civis ou desastres ambientais.

Enfim, todo esse cenário traz mudanças quantitativas e qualitativas para o professor que, mesmo assim, não possui respaldo para a atuação junto a essas crianças. Ressaltamos com isso que, para o professor ter condições de garantir o direito à educação para crianças imigrantes ou refugiadas, é necessário que ele tenha apoio do Estado nas três esferas: federal, estadual e municipal, e das universidades, considerando a possibilidade de abordar o tema na formação inicial. Caso essas áreas não estejam em complementaridade, o professor terá dificuldades de exercer seu papel com efetividade. Eventualmente, ele poderá ter respaldo da equipe diretiva de sua escola, mas, ainda assim, em um processo de tentativas, erros e acertos. A consequência 
disso é a possível ocorrência de um processo de culpabilização do professor no caso de evasão escolar, reprovação ou má assimilação de conteúdos pela criança.

\section{REFERÊNCIAS}

ACNUR. Missign Out: refugee Education in crisis. 2016. Disponível em: https://www.unhcr.org/missing-out-state-of-education-for-the-worlds-refugees.html. Acesso em: 02 nov. 2020.

ACNUR. Número de refugiados e migrantes da Venezuela no mundo atinge 3,4 milhões. Nações Unidas Brasil, 22 fev. 2019. Disponível em: https://www.acnur.org/portugues/2019/02/25/numero-de-refugiados-e-migrantes-davenezuela-no-mundo-atinge-34-milhoes/. Acesso em: 13 dez. 2020.

ALEXANDRE, Ivone Jesus. “Aquela preta não é minha amiga!”: interação e socialização de crianças haitianas nas escolas de Educação Infantil em Sinop/MT. In: REUNIÃO

NACIONAL ANPED, 38, 2017, São Luís. Anais [...]. São Luís: 2017. Disponível em: http://38reuniao.anped.org.br/sites/default/files/resources/programacao/trabalho_38anped_201 7_GT21_1298.pdf. Acesso em: 04 jan. 2021.

ARAÚJO, Danuse da Porciúncula; CONTRERAS, Humberto Silvano H. A criança imigrante e a escola: adaptação social e curricular. In: EDUCERE: CONGRESSO NACIONAL DE EDUCAÇÃO, 13, 2017, Curitiba. Anais [...]. Curitiba: 2017. Disponível em: http://38reuniao.anped.org.br/sites/default/files/resources/programacao/trabalho_38anped_201 7_GT21_1298.pdf. Acesso em: 04 jan. 2021.

ASSUMPÇÃO, Adriana Maria; AGUIAR, Gabriela de Azevedo. "Você precisa falar português com seu filho": desafios para o processo de inclusão de crianças imigrantes em escolas do Rio de Janeiro. Revista Iberoamericana de Educación, v. 81, n. 1, p. 167-188, 2019. Disponível em: https://rieoei.org/RIE/article/view/3541/4057. Acesso em: 16 dez. 2020.

BAUMAN, Zygmunt. Estranhos à nossa porta. Rio de Janeiro: Zahar, 2017.

BRASIL. Constituição da República Federativa do Brasil de 1988. Diário Oficial da União, Brasília, ano 126, n. 191-A, 5 out. 1988.

BRASIL. Lei federal no 8069, 13 de julho de 1990. Dispõe sobre o Estatuto da criança e do adolescente e dá outras providências. Diário Oficial da União, Brasília, 16 jul. 1990. Disponível em: http://www.planalto.gov.br/ccivil_03/leis/18069.htm. Acesso em: 15 dez. 2020.

BRASIL. Lei federal $n^{\circ}$ 9.394, 20 de dezembro de 1996. Lei de diretrizes e bases da educação nacional. Diário Oficial da União, Brasília, 20 dez. 1980. Disponível em:

http://www.planalto.gov.br/ccivil_03/leis/19394.htm. Acesso em: 15 dez. 2020.

BRASIL. Lei 13.445, de 24 de maio de 2017. Institui a Lei de Migração. Diário Oficial da União, Brasília, 25 maio. 2017. Disponível em:

http://www.planalto.gov.br/ccivil_03/_ato2015-2018/2017/lei/113445.htm. Acesso em: 14 nov. 2020. 
BRASIL. Decreto $n^{\circ} 528$, de 28 de junho de 1890. Regulariza o serviço da introdução e localização de imigrantes na República dos Estados Unidos do Brasil. Coleção de Leis do Brasil. Disponível em: https://www2.camara.leg.br/legin/fed/decret/1824-1899/decreto-52828-junho-1890-506935-publicacaooriginal-1-pe.html. Acesso em: 20 nov. 2020.

BRASIL. Lei n ${ }^{\circ} 9.474$, de 22 de julho de 1997. Define mecanismos para a implementação do Estatuto dos Refugiados de 1951, e determina outras providências. Diário Oficial da União, Brasília, 22 jul. 1997. Disponível em: http://www.planalto.gov.br/ccivil_03/Leis/L9474.htm. Acesso em: 10 nov. 2020.

BRONER, Tamara Taraciuk. The Venezuelan Exodus: the need for a regional response to an unprecedented migration crisis. Estados Unidos: Human Rights Watch, 2018. Disponível em: https://www.hrw.org/report/2018/09/04/venezuelan-exodus/need-regional-responseunprecedented-migration-crisis. Acesso em: 18 nov. 2020.

CANO, Wilson. Raizes da Concentração Industrial em São Paulo. Campinas: Unicamp Instituto de Economia, 5. ed., 2007.

DELFIM, Rodrigo Borges. Migrações, Refúgio e Apatridia - Guia para comunicadores. São Paulo: MigraMundo, 2019.

DEMARTINI, Zélia de Brito F. Imigração e educação: discutindo algumas pistas de pesquisa. Pro-Proposições, São Paulo, v. 15, n. 3(45), p. 215-228, set./dez. 2004. Disponível em: https://periodicos.sbu.unicamp.br/ojs/index.php/proposic/article/view/8643802/11294. Acesso em: 25 nov. 2020.

FREITAS, Marcos Cezar de; SILVA, Ana Paula. Crianças bolivianas na educação infantil de São Paulo: adaptação, vulnerabilidades e tensões. Cad. Pesqui., São Paulo, v. 45, n. 157, p. 680-702, Set. 2015. Disponível em: https://www.scielo.br/pdf/cp/v45n157/1980-5314-cp-45157-00680.pdf. Acesso em: 13 nov. 2020.

GODOY, Gabriel Gualano. O caso dos haitianos no Brasil e a via de proteção humanitária complementar. In: RAMOS, André de Carvalho; RODRIGUES, Gilberto; ALMEIDA, Guilherme de Assis (Orgs.). 60 anos de ACNUR - Perspectivas de futuro. São Paulo: Editora CL-A Cultural, 2011. Cap. 1, p. 45-68.

HIROMI, Fabiana; GOIS, Antônio. O papel da gestão no acolhimento de alunos imigrantes. São Paulo: Aprendizagem em Foco, 2018.

HOBSBAWN, Eric. Globalização, Democracia e Terrorismo. São Paulo: Companhia das Letras, 2007.

IANNI, Octávio. Dialética e capitalismo. 3. ed. Petrópolis: Vozes, 1982.

IANNI, Octávio. Raças e Classes Sociais no Brasil. 3. ed. São Paulo: Brasiliense, 1987.

KREUTZ, Lúcio. A educação de imigrantes no Brasil. In: LOPES, Eliane Marta Teixeira; FILHOS, Luciano Mendes Faria; VEIGA, Cyntia Greive (Orgs.). 500 anos de Educação no Brasil. 2. ed. Belo Horizonte: Autêntica, 2000a, p. 347-370. 
KREUTZ, Lúcio. Escolas comunitárias de imigrantes no Brasil: instâncias de coordenação e estruturas de apoio. Revista Brasileira de Educação, n. 15, p. 159-176, set-dez. 2000 b. Disponível em: https://www.scielo.br/pdf/rbedu/n15/n15a10.pdf. Acesso em: 29 nov. 2020.

KURZ, Robert. Barbárie, migrações e guerras de ordenamento mundial. In: Serviço Pastoral dos Migrantes (Org.). Travessias na desordem global: Fórum Social das Migrações. São Paulo: Paulinas, 2005, p. 25-36.

LUSSI, Carmem. Teorias da Mobilidade Humana. In: DURAND, Jorge; LUSSI, Carmem (Orgs.). Metodologia e Teorias no Estudo das Migrações. Jundiaí: Paco editorial, 2015, p. 43112.

MARINEIS, Merçon. Imigrantes bolivianos no trabalho escravo contemporâneo: análise do caso Zara a partir dos RPGs. Periódico do Centro de Estudos em Desenvolvimento Sustentável da UNDB, São Luís, v. 1, n. 2, p. 1-23, mar-jul. 2015. Disponível em: http://sou.undb.edu.br/public/publicacoes/revceds_n_2_imigrantes_bolivianos_e trabalho_es cravo_contemporaneo_caso_zara_marineis_mercon.pdf. Acesso em: 28 nov. 2020.

MARTINS, José de Souza. O cativeiro da terra. São Paulo: Contexto, 9. ed., 2010.

MARX, Karl; ENGELS, Friedrich. O manifesto Comunista. São Paulo: Paz e Terra, 4. ed., 1998.

MARX, Karl; ENGELS, Friedrich. A Ideologia Alemã. São Paulo: Martins Fontes, 2. ed., 2001.

MARX, Karl. Crítica do Programa de Gotha. São Paulo: Boitempo Editorial, 2012.

MORALES, Maureen Taft. Haiti's Political and Economic Conditions. Congressional Research Service, Washington, EUA, abr. 2019. Disponível em:

https://fas.org/sgp/crs/row/R45034.pdf . Acesso em: 20 nov. 2020.

NORÕES, Kátia Cristina. De criança a migrante, de migrante a estrangeira(o): reflexões sobre a educação pública e as migrações internacionais. In: MAZA, Débora; NORÕES, Katia Cristina (Orgs.). Educação e Migrações Internas e Internacionais. Jundiaí: Paco editorial, 2016, p. 183-203.

OIM. Diagnóstico regional sobre migración haitiana 2017. Disponível em: https://robuenosaires.iom.int/sites/default/files/publicaciones/Diagnostico_Regional.pdf. Acesso em: 10 nov. 2020.

OIM. World Migration Report 2018. Disponível em: https://publications.iom.int/system/files/pdf/wmr_2018_en.pdf . Acesso em: 10 dez. 2020.

ONU. Seis meses após o terremoto, ONU aponta situação do Haiti. Nações Unidas Brasil, 12, jul. 2010. Disponível https://brasil.un.org/index.php/pt-br/66919-seis-meses-apos-terremotoonu-aponta-situacao-do-haiti. Acesso em: 20 nov. 2020.

PAYET, Jean-Paul. Imigração e Escola. In: ZANTEN, Agnès Van (Org.). Dicionário de educação. Petrópolis: Vozes, 2011. p. 465-471. 
RAMOS, Érika Pires. Refugiados ambientais: em busca de reconhecimento pelo direito internacional. 2011. 150 f. Tese (Doutorado em Direito) - Programa de Pós-Graduação em Direito. Universidade de São Paulo, São Paulo, 2011. Disponível em: https://www.acnur.org/fileadmin/Documentos/portugues/eventos/Refugiados_Ambientais.pdf. Acesso em: 20 dez. 2020.

SCHMIDT, Alice Krämer Iorra; PICCININI, Marta Luisa; VOLKMER, Márcia Solange. O Acesso à educação aos imigrantes haitianos em uma escola pública de Arroio do Meio. Revista Signos, v. 37, n. 2, p. 25-39, jul-dez. 2016. Disponível em: http://www.univates.br/revistas/index.php/signos/article/view/1102/1061. Acesso em: 04 jan. 2021.

SÃO PAULO (MUNICÍPIO). Lei $n^{o}$ 16.478, de 8 de julho de 2016. Institui a Política Municipal para a População Imigrante, dispõe sobre seus objetivos, princípios, diretrizes e ações prioritárias, bem como sobre o Conselho Municipal de Imigrantes. Disponível em: http://documentacao.camara.sp.gov.br/iah/fulltext/leis/L16478.pdf. Acesso em: 15 dez. 2020.

SÃO PAULO (MUNICÍPIO). Núcleo para a Educação das Relações Étnico-Raciais. 2005. Disponível em: http://portal.sme.prefeitura.sp.gov.br/Main/Page/PortalSMESP/EducacaoetnicoRacial. Acesso em: 10 dez. 2020.

SAYAD, Abdelmalek. A Imigração ou os Paradoxos da Alteridade. São Paulo: Edusp, 1998.

SILVA, Sidney Antônio da. Bolivianos em São Paulo: entre o sonho e a realidade. Estudos Avançados, São Paulo, v. 20, n. 57, p. 157-170, mai./ago. 2006. Disponível em: https://www.scielo.br/pdf/ea/v20n57/a12v2057.pdf. Acesso em: 15 dez. 2020.

VAINER, Carlos Bernardo. Estado e Migrações no Brasil: anotação para uma história das políticas migratórias. Travessia - revista do migrante, São Paulo, n. 36, p. 15-32, jan./abr. 2000 .

\section{SOBRE O AUTOR E A AUTORA}

Rômulo Sousa de Azevedo é Mestre em Educação pela Universidade Federal de Goiás, e servidor técnico-administrativo do Instituto Federal de Goiás - Campus Cidade de Goiás. Integra a Redecentro Rede de Pesquisadores sobre o Professor(a) na Região Centro-Oeste.

E-mail: romulo.sousadm@gmail.com

ORCID: https://orcid.org/0000-0001-9959-5363

Cláudia Tavares do Amaral é Doutora em Educação pela Universidade de Lisboa, Professora da Universidade Federal de Catalão (UFCAT); do Programa de Pós-Graduação em Educação na Linha de Pesquisa: Práticas Educativas, Formação de Professores e Inclusão. Integra a Redecentro - Rede de Pesquisadores sobre o Professor(a) na Região Centro-Oeste.

E-mail: claudiatamaral@gmail.com

ORCID: https://orcid.org/0000-0003-2859-9353 